\title{
Surfactant-Templated Mesoporous Metal Oxide Nanowires
}

\author{
Hongmei Luo, Qianglu Lin, Stacy Baber, and Mahesh Naalla \\ Department of Chemical Engineering, New Mexico State University, Las Cruces, NM 88003, USA \\ Correspondence should be addressed to Hongmei Luo, hluo@nmsu.edu
}

Received 29 September 2009; Accepted 6 December 2009

Academic Editor: Chao Lin

Copyright (C) 2010 Hongmei Luo et al. This is an open access article distributed under the Creative Commons Attribution License, which permits unrestricted use, distribution, and reproduction in any medium, provided the original work is properly cited.

We demonstrate two approaches to prepare mesoporous metal oxide nanowires by surfactant assembly and nanoconfinement via sol-gel or electrochemical deposition. For example, mesoporous $\mathrm{Ta}_{2} \mathrm{O}_{5}$ and zeolite nanowires are prepared by block copolymer Pluronic 123-templated sol-gel method, and mesoporous $\mathrm{ZnO}$ nanowires are prepared by electrodeposition in presence of anionic surfactant sodium dodecyl sulfate (SDS) surfactant, in porous membranes. The morphologies of porous nanowires are studied by scanning electron microscopy (SEM) and transmission electron microscopy (TEM) analyses.

\section{Introduction}

One-dimensional (1D) nanostructures have become the focus of intensive research owing to their potential applications as building blocks for nanoelectronic and nanophotonic devices $[1,2]$. A lot of synthesis strategies have been developed to fabricate $1 \mathrm{D}$ nanostructures with various compositions, controlled morphologies, and complex architectures [3]. Template synthesis is one of the well-established strategies where porous anodized aluminum oxide (AAO) membranes are often used as alternative templates for making nanowire arrays [4].

Mesostructured materials with well-defined pore structures and uniform pore sizes attract much attention [58]. Surfactant templating strategy through cooperative selfassembly of inorganic species and surfactant is a basic synthetic powerful approach to fabricate ordered mesostructured materials. Recently, by confined self-assembly of surfactant in cylindrical pore channels of AAO membranes, hierarchically mesoporous silica nanowires or nanotubes with different morphologies have been fabricated [9-21]. These hierarchical structures can be further used as hard templates to host and guide the growth of aligned and ordered metal and semiconductor 1D nanostructures [22, 23]. Those mesoporous nanowires are particular attractive for sensor and catalyst applications because of their hierarchically organized structure, tunable pore size, and higher surface area. However, only a few studies have been carried out to directly confine the nonsilica mesoporous materials in the cylindrical pore channels [24].

In this study, we will report that mesoporous metal oxide nanowires can be prepared by surfactant confined in porous membranes via sol-gel or electrodeposition approach. More specifically, the overall diameter of nanowires is defined by the cylindrical AAO pore channels. Surfactant nanoconfined in AAO is used to generate mesoporosity and to control the texture of nanowires. Here we use mesoporous $\mathrm{Ta}_{2} \mathrm{O}_{5}$ and zeolite by sol-gel and $\mathrm{ZnO}$ nanowires by electrodeposition as examples. $\mathrm{Ta}_{2} \mathrm{O}_{5}$ is a fascinating functional material that has been used in applications such as dynamic random access memory (DRAM) devices, antireflection coating layers, gas sensors, photocatalysts, and capacitors owing to its high dielectric constant, high refractive index, chemical stability, and high temperature piezoelectric properties [25-27]. Zeolite is commercially used as catalysts and separation media [28-30]. Both of mesoporous $\mathrm{Ta}_{2} \mathrm{O}_{5}$ and zeolite nanowires have not been reported so far. $\mathrm{ZnO}$ is a unique material that exhibits semiconducting and piezoelectric dual properties for wide applications in chemical sensors, laser diodes, solar cell, photocatalyst, and piezoelectric transduction [8, 31-33]. This is the first surfactant templated growth of mesoporous $\mathrm{ZnO}$ nanowires.

\section{Experimental Procedures}

Mesoporous $\mathrm{Ta}_{2} \mathrm{O}_{5}$ and zeolite nanowires were prepared by surfactant templated sol-gel method. The solution 
for mesoporous $\mathrm{Ta}_{2} \mathrm{O}_{5}$ nanowires is similar to that used for the preparation of meosporous $\mathrm{Ta}_{2} \mathrm{O}_{5}$ powder [34]. Typically, $1 \mathrm{~g}$ of block copolymer Pluronic P-123 $\left(\mathrm{HO}\left(\mathrm{CH}_{2} \mathrm{CH}_{2} \mathrm{O}\right)_{20}\left(\mathrm{CH}_{2} \mathrm{CH}\left(\mathrm{CH}_{3}\right) \mathrm{O}\right)_{70}\left(\mathrm{CH}_{2} \mathrm{CH}_{2} \mathrm{O}\right)_{20} \mathrm{H}\right.$, designed $\mathrm{EO}_{20} \mathrm{PO}_{70} \mathrm{EO}_{20}$ ) was dissolved in $5 \mathrm{~g}$ of ethanol, then $0.5 \mathrm{~g}$ of $\mathrm{TaCl}_{5}$ was added, and the solution was stirred for $0.5 \mathrm{~h}$. For mesoporous zeolite, $0.4 \mathrm{~g}$ P-123 was dissolved in $6 \mathrm{~mL}$ of $\mathrm{H}_{2} \mathrm{O}$ with $2 \mathrm{~mL}$ of $0.1 \mathrm{M} \mathrm{HCl}$, followed by $3.5 \mathrm{ml}$ of pure-silica zeolite MFI nanoparticle suspension; the solution was then stirred for 1 hour. A pure-silica zeolite MFI nanoparticle suspension was synthesized by hydrothermal method from TEOS, TPAOH, ethanol, and $\mathrm{H}_{2} \mathrm{O}$ (TEOS and TPAOH stand for tetraethylorthosilicate and tetrapropylammonium hydroxide, resp.) as starting materials. The molar composition of the synthesis solution was $1 \mathrm{TPAOH} / 3 \quad \mathrm{SiO}_{2} / 25.1 \mathrm{EtOH} / 52.4 \quad \mathrm{H}_{2} \mathrm{O}[28,29]$. It is noted that complete in situ hydrolysis of TEOS would produce $11.2 \mathrm{~mol}$ of EtOH. TEOS, ethanol, and $\mathrm{H}_{2} \mathrm{O}$ were first mixed together and stirred for 0.5 hour, TPAOH was then added slowly into the solution. The clear solution thus obtained was aged in a capped plastic vessel for 3 days at room temperature followed by heating at $100^{\circ} \mathrm{C}$ for another 7 days with stirring. The zeolite nanoparticle suspension after cooling to room temperature was then centrifuged at $5000 \mathrm{rpm}$ for 20 minutes to remove big particles, and then passed through $0.2 \mu \mathrm{m}$ HT Tuffryn syringe filter. This solution will be used to mix with P-123 to make mesoporous zeolite nanowires.

Commercial AAO membranes with pore diameter of 20 or $100 \mathrm{~nm}$ and thickness of $60 \mu \mathrm{m}$ thickness were immersed in the above P-123 assembly sol-gel solutions for overnight. Then the membranes were dry and calcined at $400^{\circ} \mathrm{C}$ for 5 hours to remove P-123; nanowires were then dispersed in ethanol after removing $\mathrm{AAO}$ membrane by $2 \mathrm{M} \mathrm{NaOH}$ and cleaning by $\mathrm{DI} \mathrm{H}_{2} \mathrm{O}$.

Mesoporous $\mathrm{ZnO}$ nanowires were prepared by surfactant templated electrodeposition. The electrodeposition was performed in a standard three-electrode glass cell, which was immersed in a water bath held at $65^{\circ} \mathrm{C} .100 \mathrm{~nm}$ thick Au-coated porous polycarbonate membrane $(50 \mathrm{~nm}$ pore size and $6 \mu \mathrm{m}$ thickness) or AAO (100 nm pore size and $60 \mu \mathrm{m}$ thickness) was used as the cathode while $\mathrm{Pt}$ gauze as the anode and $\mathrm{Ag} / \mathrm{AgCl}$ electrode as the reference electrode ( $U_{\text {eq }}=0.215 \mathrm{~V}$ standard hydrogen electrode, $\left.\mathrm{SHE}\right)$. $\mathrm{ZnO}$ was electrodeposited at $-0.9 \mathrm{~V}$ versus $\mathrm{Ag} / \mathrm{AgCl}$ from $0.05 \mathrm{M} \mathrm{Zn}\left(\mathrm{NO}_{3}\right)_{2}$. $\mathrm{ZnO}$ nanowires were electrodeposited from 0, 0.5, 5, and $20 \mathrm{wt} \%$ SDS surfactant in $0.05 \mathrm{M}$ $\mathrm{Zn}\left(\mathrm{NO}_{3}\right)_{2}$ solutions. After electrodeposition, the nanowires were stripped from the membrane templates by first dissolving Au by mercury, then dissolving polycarbonate membrane with chloroform, or AAO membrane with $2 \mathrm{M} \mathrm{NaOH}$, and followed cleaning with distilled water and ethanol by centrifugation with $4000 \mathrm{rpm}$ for several times.

The X-ray diffraction (XRD) patterns were obtained on Siemens D-500 diffractometer using $\mathrm{Cu} \mathrm{K}_{\alpha}$ radiation. Scanning electron microscopy (SEM) images were obtained on a HITACHI S4800 field emission microscope (FESEM) at $3 \mathrm{kV}$ equipped with EDX. Transmission electron microscopy (TEM) images and selected area electron diffraction (SAED)

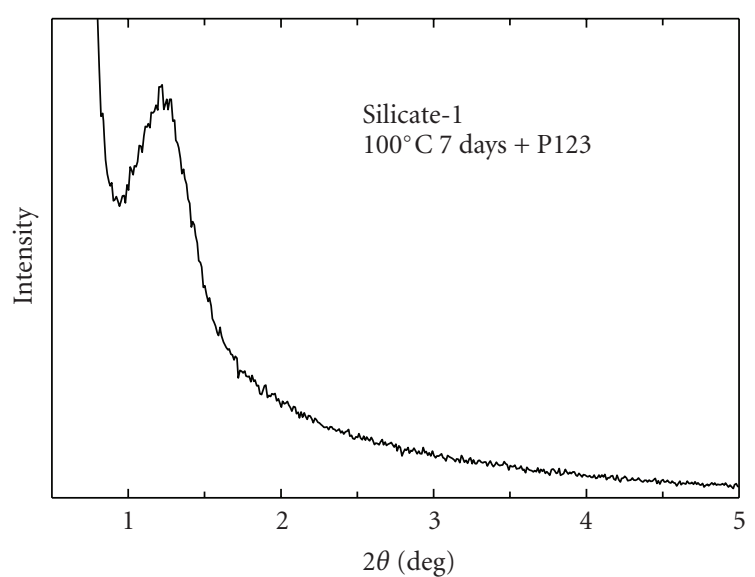

(a)

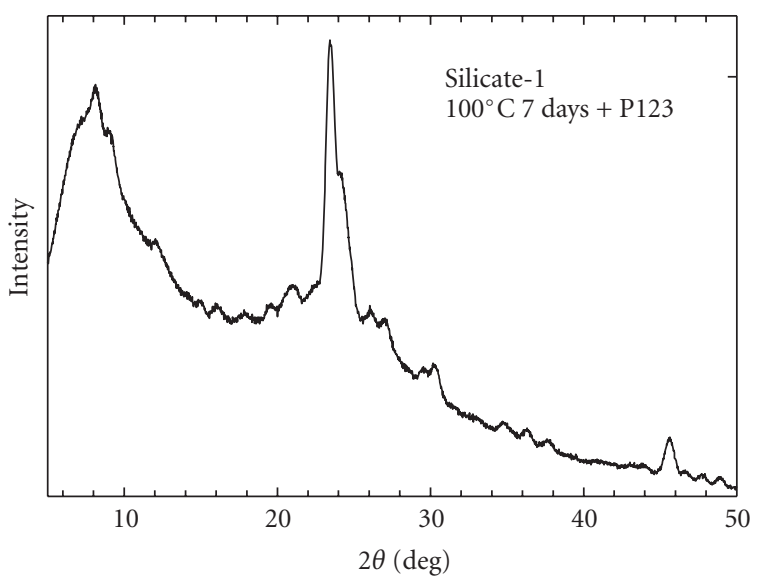

(b)

FIGURE 1: Low-angle and wide-angle XRD patterns for porous zeolite films from self-assembly of silicate- 1 zeolite MFI at $100^{\circ} \mathrm{C}$ for 7 days with P-123.

patterns were obtained on a JEOL 2010 TEM microscope equipped with Oxford Link ISIS 6498 spectrometer for energy dispersive X-ray (EDX) analysis and operated at $200 \mathrm{kV}$ to determine the nanowire morphology and structure.

\section{Results and Discussion}

Before soaking the porous membranes in the solutions, porous zeolite films were prepared from the same solution. Figure 1 shows the low-angle and wide-angle XRD patterns for films from spin-coating P-123 self-assembled zeolite MFI solution on silicon substrates and heating at $400^{\circ} \mathrm{C}$ for 2 hours. The low-angle shows typical hexagonal structure with a strong (100) diffraction peak of a d-spacing of $7.2 \mathrm{~nm}$, consistent with the surfactant P123 used, indicating mesostructure preserves in the films, however, without longrange order. The wide-angle XRD pattern shows crystalline MFI zeolite formation where the degree of crystallinity can be controlled by the solution aging and heating temperature and time. 


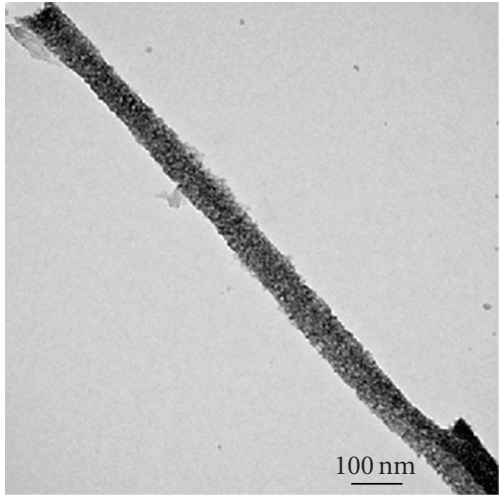

(a)

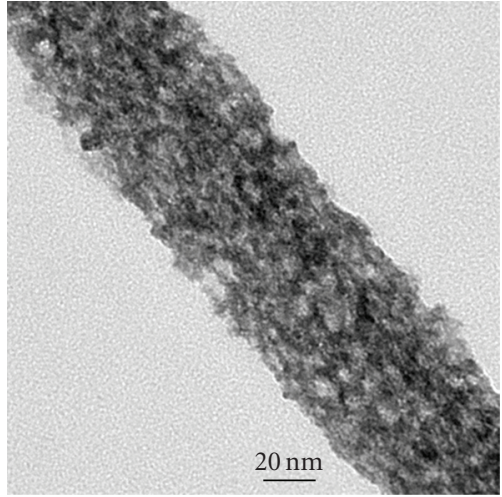

(b)

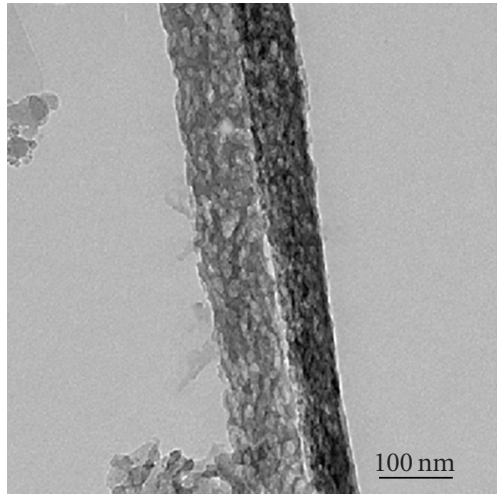

(c)

FIgURE 2: TEM images for mesoporous $\mathrm{Ta}_{2} \mathrm{O}_{5}$ nanowires $(\mathrm{a}, \mathrm{b})$ and zeolite nanowires $(\mathrm{c})$.

Mesoporous $\mathrm{Ta}_{2} \mathrm{O}_{5}$ and zeolite nanowires were obtained by soaking the porous membrane in the surfactant selfassembled sol-gel solution. The isolated nanowires were obtained by removing surfactant P-123 via the calcination and removing AAO membrane through dissolution. Figure 2 shows TEM images for mesoporous $\mathrm{Ta}_{2} \mathrm{O}_{5}$ and zeolite nanowires. The porous nanowires with diameters of 80 $100 \mathrm{~nm}$ and lengths of tens of $\mu \mathrm{m}$ were clearly visible. $\mathrm{Ta}_{2} \mathrm{O}_{5}$ nanowires are amorphous, while zeolite shows crystalline due to the longer heating time for the zeolite nanoparticle suspension. In other words, by controlling the zeolite nanoparticle suspension aging and heating conditions, the amorphous or crystalline zeolite nanowires can be formed. It is reported that amorphous mesoporous $\mathrm{Ta}_{2} \mathrm{O}_{5}$ powders were obtained from block copolymer templated sol-gel method [34]. With increasing heating temperature and time, the oxides can go from amorphous to semicrystalline to crystalline, however, the pores in oxides may be collapse at higher temperature. Here we use surfactant self-assembly nanoconfined in AAO membranes to demonstrate the formation of mesoporous metal oxide nanowires. The nanowire diameter is in consistent with the pore size of the AAO membranes, and the length of nanowires is probably dependent on the soaking time of the membranes in the solution. Surfactant assembled structure nanoconfined within the pores is used to generate porosity and to control the texture of nanowires. Here the pores in the nanowires are from P-123 while the pore size should be around $8-10 \mathrm{~nm}$, in consistent with the surfactant used. However, bigger pores were clearly observed may be due to the merging of the individual pores.

Before making the mesoporous $\mathrm{ZnO}$ nanowires, we also prepared mesoporous $\mathrm{ZnO}$ films. Figure 3(a) shows the lowangle XRD patterns for the mesoporous $\mathrm{ZnO}$ films on ITOglass electrodeposited from $0.05 \mathrm{M} \mathrm{Zn}\left(\mathrm{NO}_{3}\right)_{2}$ with 0.5 and $5 \mathrm{wt} \%$ SDS. Without surfactant, no low-angle peaks were observed. While adding SDS in the solution, low-angle XRD pattern has two sets of evenly spaced $00 l$ reflections, which are unambiguously indexed as two different lamellar phases, one with $\mathrm{d}_{001 *}=3.18 \mathrm{~nm}$ and the other with

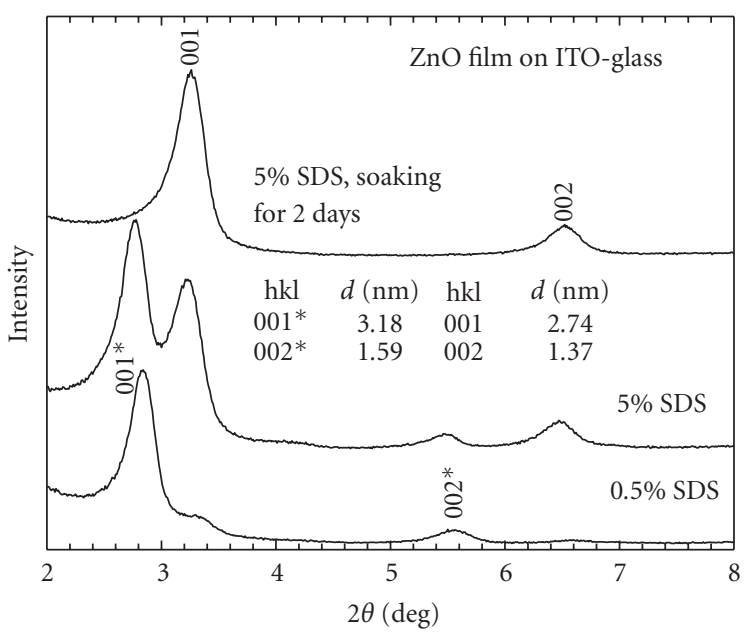

(a)

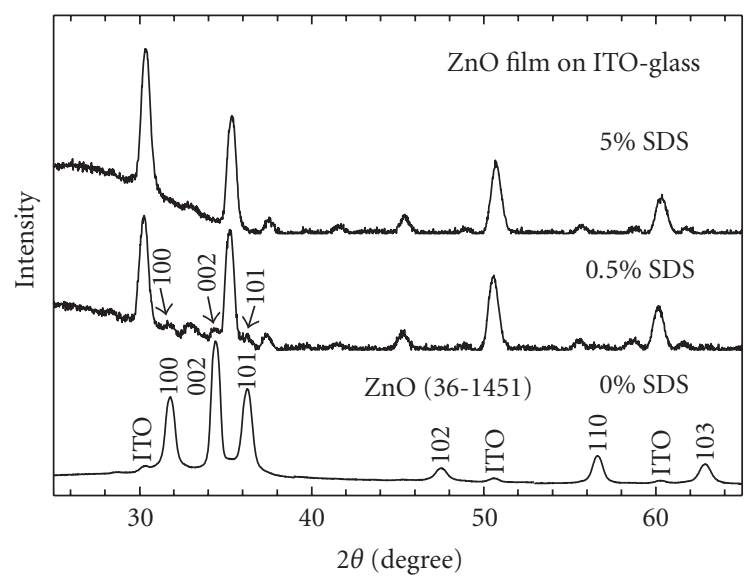

(b)

FIGURE 3: Low-angle XRD patterns for porous $\mathrm{ZnO}$ film on ITO-glass from $0.05 \mathrm{M} \mathrm{Zn}\left(\mathrm{NO}_{3}\right)_{2}$ with 0.5 and $5 \mathrm{wt} \%$ SDS via electrodeposition and after soaking in water and ethanol for 2 days; and (b) Wide-angle XRD patterns for $\mathrm{ZnO}$ films on ITO-glass from $0.05 \mathrm{M} \mathrm{Zn}\left(\mathrm{NO}_{3}\right)_{2}$ with $0,0.5$ and $5 \mathrm{wt} \%$ SDS surfactants. 


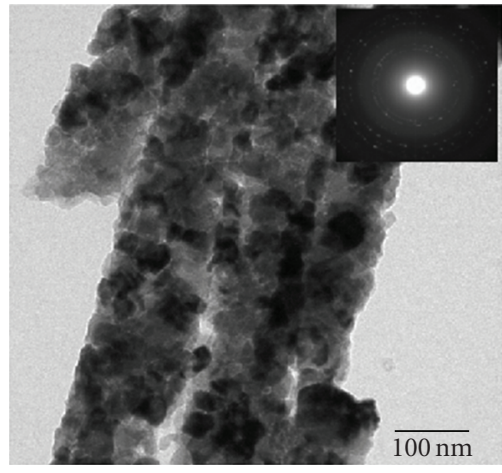

(a)

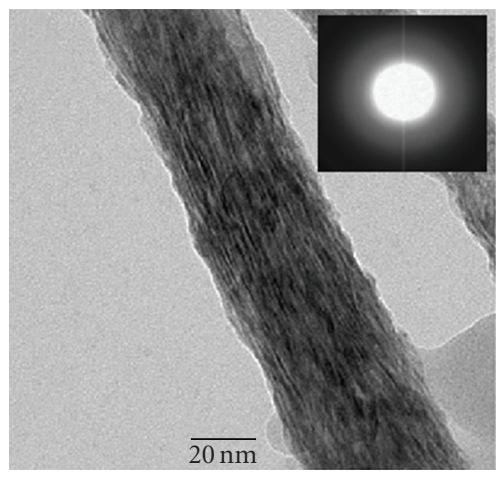

(b)

FIgURE 4: TEM images and SAED patterns for $\mathrm{ZnO}$ nanowires from $0.05 \mathrm{M} \mathrm{Zn}\left(\mathrm{NO}_{3}\right)_{2}$ without surfactant (a) and $5 \mathrm{wt} \%$ SDS in $\mathrm{Zn}\left(\mathrm{NO}_{3}\right)_{2}$ (b).

$\mathrm{d}_{001 *}=2.74 \mathrm{~nm}$, implying well-defined long-range order nanostructure preserved in the film. Identical $d$ spacing values are obtained by varying the concentration of SDS from 0.5 and $5 \mathrm{wt} \%$ SDS in aqueous solutions, indicating that the interfacial assembly pattern of surfactant-inorganic intermediates does not depend on the bulk surfactant concentration. The formation of lamellar bi-phases suggests that two different geometrical orientations of SDS- $\mathrm{Zn}^{2+}$ bilayers are formed relative to the electrode surface [8]. After film soaking in water and ethanol for 1 day, the former lamellar structure peaks intensity decreases, after further soaking for 2 days, the low-angle XRD pattern only has one family lamellar mesostructure with $\mathrm{d}_{001 *}=2.74 \mathrm{~nm}$, indicating that the former family lamellar with $\mathrm{d}_{001 *}=3.18 \mathrm{~nm}$ may not be stable and change to the latter lamellar phase with stable geometrical orientations. Figure 3(b) shows the wideangle XRD patterns for $\mathrm{ZnO}$ films on ITO-glass from $0.05 \mathrm{M} \mathrm{Zn}\left(\mathrm{NO}_{3}\right)_{2}$ and mesoporous films from the solution with 0.5 and $5 \mathrm{wt} \%$ SDS. For the pure $\mathrm{ZnO}$ film without surfactant, wide-angle XRD indicates that highly crystalline wurtzite hexagonal $\mathrm{ZnO}$ forms (JCPDS, no. 36-1451). For mesostructured $\mathrm{ZnO}$ films, the film with $0.5 \mathrm{wt} \%$ SDS still shows weak crystalline. However, with increasing SDS amount to $5 \mathrm{wt} \%$, except the substrate ITO-glass peaks, we no longer see crystalline $\mathrm{ZnO}$ peaks, indicating, $\mathrm{ZnO}$ is amorphous. This result suggests that under the influence of

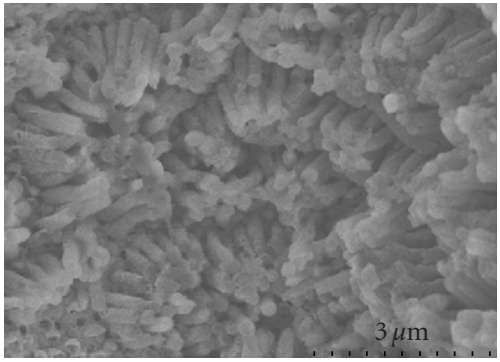

(a)

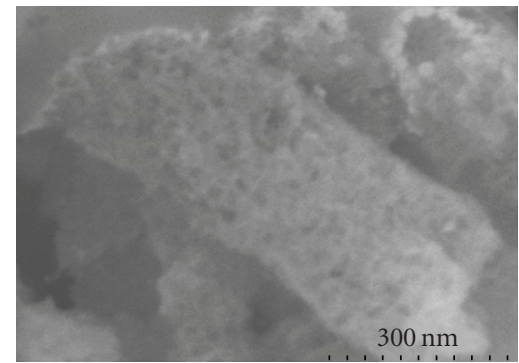

(b)

FIGURE 5: FESEM images for mesoporous $\mathrm{ZnO}$ nanowires from $0.05 \mathrm{M} \mathrm{Zn}\left(\mathrm{NO}_{3}\right)_{2}$ with $20 \mathrm{wt} \%$ SDS after dissolution of the alumina template membrane.

an electrostatic potential, surfactant-inorganic species selfassembly and electrodeposition occurs on the surface of the ITO-glass cathod, amorphous $\mathrm{ZnO}$ films with lamellar mesostructure can be produced.

Mesoporous $\mathrm{ZnO}$ nanowires were formed when selfassembly of surfactants confined within cylindrical pore channels via electrodeposition. Figure 4 shows TEM images and SAED patterns for $\mathrm{ZnO}$ nanowires electrodeposited from $0.05 \mathrm{M} \mathrm{Zn}\left(\mathrm{NO}_{3}\right)_{2}$ with 0 and $5 \mathrm{wt} \%$ SDS surfactant. The images clearly see nanowires formation with diameters of $80-100 \mathrm{~nm}$ and lengths of up to $1 \mu \mathrm{m}$. It is well known that the nanowire diameter can be tuned by different pore size membrane templates, and the wire length can be easily controlled from nm to $\mu \mathrm{m}$ by electrodeposition time. However, due to semiconducting behavior of $\mathrm{ZnO}$, the nanowires are not easily to grow as long as the porous membrane thickness as metals or other conducting materials. EDX analysis shows that the nanowires contain $\mathrm{Zn}$ and O. SDS surfactant can be removed by thoroughly washing with water and ethanol, but the nanowires may be broken by mechanical force such as ultrasonication. Without surfactants in the electrolytes, the crystalline $\mathrm{ZnO}$ nanowires can be electrodeposited. SAED pattern shows the crystalline $\mathrm{ZnO}$ formation. With further increasing SDS to $5 \mathrm{wt} \%$, SAED pattern indicates that $\mathrm{ZnO}$ is amorphous, and the images clearly exhibit the ordered lamellar mesostructure with pore size of $2.5 \mathrm{~nm}$, in consistent with SDS surfactant size [8]. The amorphous nature of the nanowires is in consistent with the amorphous films determined by XRD in Figure 3(b).

Figure 5 shows FESEM images for the mesoporous $\mathrm{ZnO}$ nanowires deposited from $20 \mathrm{wt} \%$ SDS in $\mathrm{Zn}\left(\mathrm{NO}_{3}\right)_{2}$ after 
dissolving the membranes. Highly ordered mesoporous nanowire arrays were obtained with $200 \mathrm{~nm}$ in diamaters and $1-2 \mu \mathrm{m}$ in lengths and one can clearly see the porosity and mesostructure from the nanowires (Figure 5(b)).

Confinement on the lamellar liquid crystal assembly from block copolymers or silica-surfactant nanocomposite in the nanoscale pores has been extensively studied both theortically and experimentally [9-11]. These lamellar mesostructure with the layers are parallel to the substrates; nanoconfinement in nanoscale pores results in the coaxially concentric multilayered cylindrical mesophase by curling the layered structures to diminish the interfacial curvatures [911]. However, different from the above lamellar mesophase, upon the addition of the anionic surfactant SDS into an inorganic electrolyte solutions $\mathrm{Zn}\left(\mathrm{NO}_{3}\right)_{2}$, the electrostatic interaction results in the formation of an interface $\left(\mathrm{S}^{-} \mathrm{I}^{+}\right)$, comprised of metal cations and anionic headgroups of surfactants. The metal cations adsorb on the electrode surface, when applying a potential between a working and counter electrodes, the interface will stack layer by layer and the surfactants pack parallel to each other, perpendicular to the substrate. Two-dimensional grazing-incidence smallangle X-ray scattering (SAXS) technique proves the mesoporous $\mathrm{ZnO}$ films with the layers stacked not parallel to the substrate, different from the sol-gel self-assembly method [8]. Thus mesostructured nanowires (not nanotubes) are electrodeposited when the surface self-assembly is confined in the nanoscale pores.

\section{Conclusions}

In conclusion, by combination of surfactant self-assembly, nanoconfinement and sol-gel or electrodeposition, mesoporous $\mathrm{Ta}_{2} \mathrm{O}_{5}$, zeolites and $\mathrm{ZnO}$ nanowires are produced. These novel approaches could be extended to prepare some other metal oxide porous nanowires. The controlled pore size and morphology nanostructured nanowires may have applications in optical and electric nanodevices.

\section{Acknowledgments}

The authors gratefully acknowledge the supports from the New Mexico Consortium, Los Alamos Institute for Advanced Studies (IAS), and Center for Integrated Nanotechnologies (CINT) at Los Alamos National Laboratory.

\section{References}

[1] C. M. Lieber, "Nanoscale science and technology: building a big future from small things," MRS Bulletin, vol. 28, no. 7, pp. 486-491, 2003.

[2] S. Jin, D. Whang, M. C. McAlpine, R. S. Friedman, Y. Wu, and C. M. Lieber, "Scalable interconnection and integration of nanowire devices without registration," Nano Letters, vol. 4, no. 5, pp. 915-919, 2004.

[3] Y. N. Xia, P. D. Yang, Y. G. Sun, et al., "One-dimensional nanostructures: synthesis, characterization, and applications," Advanced Materials, vol. 15, no. 5, pp. 353-389, 2003.
[4] C. R. Martin, "Nanomaterials: a membrane-based synthetic approach," Science, vol. 266, no. 5193, pp. 1961-1966, 1994.

[5] Y. Lu, "Surfactant-templated mesoporous materials: from inorganic to hybrid to organic," Angewandte Chemie International Edition, vol. 45, no. 46, pp. 7664-7667, 2006.

[6] C. J. Brinker and D. R. Dunphy, "Morphological control of surfactant-templated metal oxide films," Current Opinion in Colloid \& Interface Science, vol. 11, no. 2-3, pp. 126-132, 2006.

[7] Y. Lu, R. Ganguli, C. A. Drewien, et al., "Continuous formation of supported cubic and hexagonal mesoporous films by sol-gel dip-coating," Nature, vol. 389, no. 6649, pp. 364-368, 1997.

[8] K.-S. Choi, H. C. Lichtenegger, G. D. Stucky, and E. W. McFarland, "Electrochemical synthesis of nanostructured $\mathrm{ZnO}$ films utilizing self-assembly of surfactant molecules at solid-liquid interfaces," Journal of the American Chemical Society, vol. 124, no. 42, pp. 12402-12403, 2002.

[9] Z. Yang, Z. Niu, X. Cao, et al., "Template synthesis of uniform 1D mesostructured silica materials and their arrays in anodic alumina membranes," Angewandte Chemie International Edition, vol. 42, no. 35, pp. 4201-4203, 2003.

[10] A. Yamaguchi, F. Uejo, T. Yoda, et al., "Self-assembly of a silicasurfactant nanocomposite in a porous alumina membrane," Nature Materials, vol. 3, no. 5, pp. 337-341, 2004.

[11] Y. Wu, G. Cheng, K. Katsov, et al., "Composite mesostructures by nano-confinement," Nature Materials, vol. 3, no. 11, pp. 816-822, 2004.

[12] J. Wang, C.-K. Tsung, W. Hong, Y. Wu, J. Tang, and G. D. Stucky, "Synthesis of mesoporous silica nanofibers with controlled pore architectures," Chemistry of Materials, vol. 16, no. 24, pp. 5169-5181, 2004.

[13] J. F. Wang, C.-K. Tsung, R. C. Hayward, Y. Wu, and G. D. Stucky, "Single-crystal mesoporous silica ribbons," Angewandte Chemie International Edition, vol. 44, no. 2, pp. 332336, 2004.

[14] Q. Y. Lu, F. Gao, S. Komarneni, and T. E. Mallouk, "Ordered SBA-15 nanorod arrays inside a porous alumina membrane," Journal of the American Chemical Society, vol. 126, no. 28, pp. 8650-8651, 2004.

[15] Z. Liang and A. S. Susha, "Mesostructured silica tubes and rods by templating porous membranes," Chemistry: A European Journal, vol. 10, no. 19, pp. 4910-4914, 2004.

[16] B. D. Yao, D. Fleming, M. A. Morris, and S. E. Lawrence, "Structural control of mesoporous silica nanowire arrays in porous alumina membranes," Chemistry of Materials, vol. 16, no. 24, pp. 4851-4855, 2004.

[17] K. W. Jin, B. Yao, and N. Wang, "Structural characterization of mesoporous silica nanowire arrays grown in porous alumina templates," Chemical Physics Letters, vol. 409, no. 4-6, pp. 172176, 2005.

[18] D. Wang, R. Kou, Z. Yang, J. He, Z. Yang, and Y. Lu, "Hierachical mesoporous silica wires by confined assembly," Chemical Communications, no. 2, pp. 166-167, 2005.

[19] A. Y. Ku, S. T. Taylor, and S. M. Loureiro, "Mesoporous silica composites containing multiple regions with distinct pore size and complex pore organization," Journal of the American Chemical Society, vol. 127, no. 19, pp. 6934-6935, 2005.

[20] W. P. Zhu, Y. C. Han, and L. J. An, "Synthesis of ordered mesostructured silica nanotubal arrays," Microporous and Mesoporous Materials, vol. 84, no. 1-3, pp. 69-74, 2005.

[21] B. Platschek, N. Petkov, and T. Bein, "Tuning the structure and orientation of hexagonally ordered mesoporous channels 
in anodic alumina membrane hosts: a 2D small-angle X-ray scattering study," Angewandte Chemie International Edition, vol. 45, no. 7, pp. 1134-1138, 2006.

[22] Y. Wu, T. Livneh, Y. X. Zhang, et al., "Templated synthesis of highly ordered mesostructured nanowires and nanowire arrays," Nano Letters, vol. 4, no. 12, pp. 2337-2342, 2004.

[23] N. Petkov, B. Platschek, M. A. Morris, J. D. Holmes, and T. Bein, "Oriented growth of metal and semiconductor nanostructures within aligned mesoporus channels," Chemistry of Materials, vol. 19, no. 6, pp. 1376-1381, 2007.

[24] W. H. Lai, J. Shieh, L. G. Teoh, and M. H. Hon, "Fabrication of one-dimensional mesoporous tungsten oxide," Nanotechnology, vol. 17, no. 1, pp. 110-115, 2006.

[25] S. Ezhilvalavan and T. Y. Tseng, "Preparation and properties of tantalum pentoxide $\left(\mathrm{Ta}_{2} \mathrm{O}_{5}\right)$ thin films for ultra large scale integrated circuits (ULSIs) application: a review," Journal of Materials Science: Materials in Electronics, vol. 10, no. 1, pp. 9-31, 1999.

[26] Y. Zhu, F. Yu, Y. Man, Q. Tian, Y. He, and N. Wu, "Preparation and performances of nanosized $\mathrm{Ta}_{2} \mathrm{O}_{5}$ powder photocatalyst," Journal of Solid State Chemistry, vol. 178, no. 1, pp. 224-229, 2005.

[27] Y.-L. Chueh, L.-J. Chou, and Z. L. Wang, " $\mathrm{SiO}_{2} / \mathrm{Ta}_{2} \mathrm{O}_{5}$ core-shell nanowires and nanotubes," Angewandte Chemie International Edition, vol. 45, no. 46, pp. 7773-7778, 2006.

[28] Z. B. Wang, H. T. Wang, A. Mitra, L. M. Huang, and Y. S. Yan, "Pure-silica zeolite low-k dielectric thin films," Advanced Materials, vol. 13, no. 10, pp. 746-749, 2001.

[29] S. Li, Z. Li, D. Medina, C. Lew, and Y. Yan, "Organicfunctionalized pure-silica-zeolite MFI low-k films," Chemistry of Materials, vol. 17, no. 7, pp. 1851-1854, 2005.

[30] S. Ivanova, B. Louis, M.-J. Ledoux, and C. Pham-Huu, "Autoassembly of nanofibrous zeolite crystals via silicon carbide substrate self-transformation," Journal of the American Chemical Society, vol. 129, no. 11, pp. 3383-3391, 2007.

[31] P. X. Gao, Y. Ding, W. Mai, W. L. Hughes, C. S. Lao, and Z. L. Wang, "Materials science: conversion of zinc oxide nanobelts into superlattice-structured nanohelices," Science, vol. 309, no. 5741, pp. 1700-1704, 2005.

[32] Z. L. Wang and J. Song, "Piezoelectric nanogenerators based on zinc oxide nanowire arrays," Science, vol. 312, no. 5771, pp. 242-246, 2006.

[33] X. Wang, C. J. Summers, and Z. L. Wang, "Mesoporous singlecrystal $\mathrm{ZnO}$ nanowires epitaxially sheathed with $\mathrm{Zn}_{2} \mathrm{SiO}_{4}$," Advanced Materials, vol. 16, no. 14, pp. 1215-1218, 2004.

[34] P. D. Yang, D. Y. Zhao, D. I. Margolese, B. F. Chmelka, and G. D. Stucky, "Block copolymer templating syntheses of mesoporous metal oxides with large ordering lengths and semicrystalline framework," Chemistry of Materials, vol. 11, no. 10 , pp. 2813-2826, 1999. 

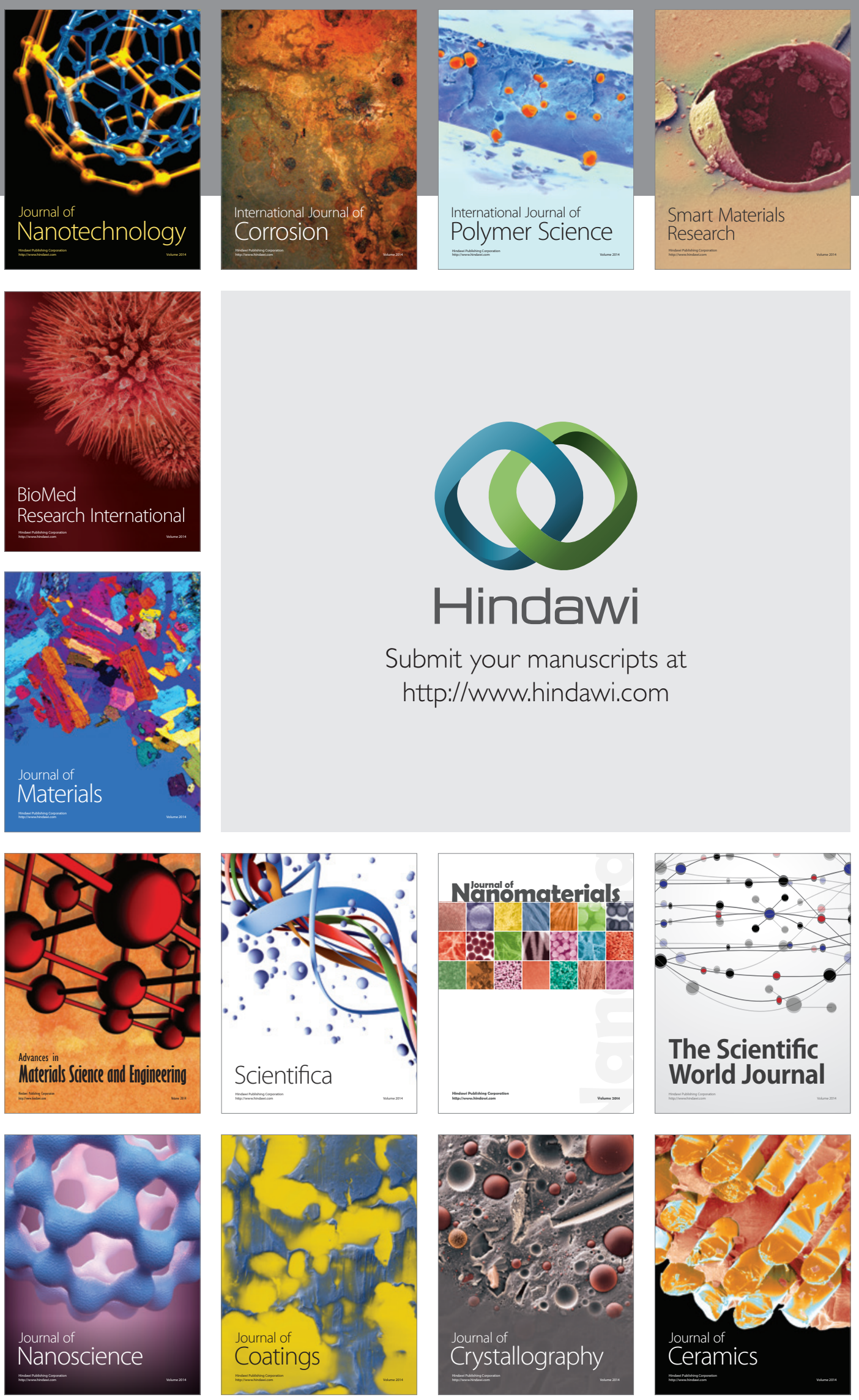

The Scientific World Journal

Submit your manuscripts at

http://www.hindawi.com

\section{World Journal}

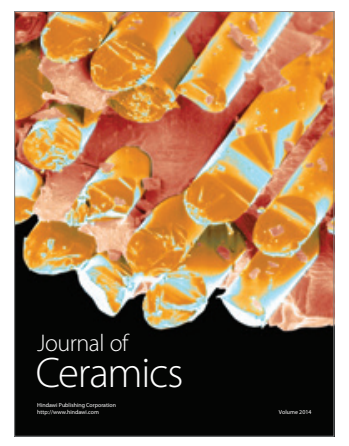

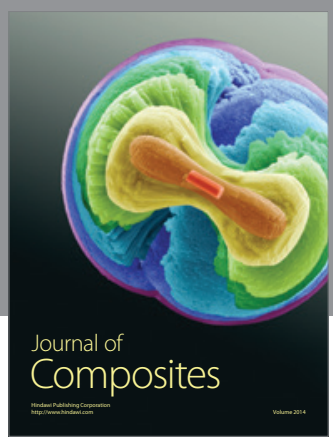
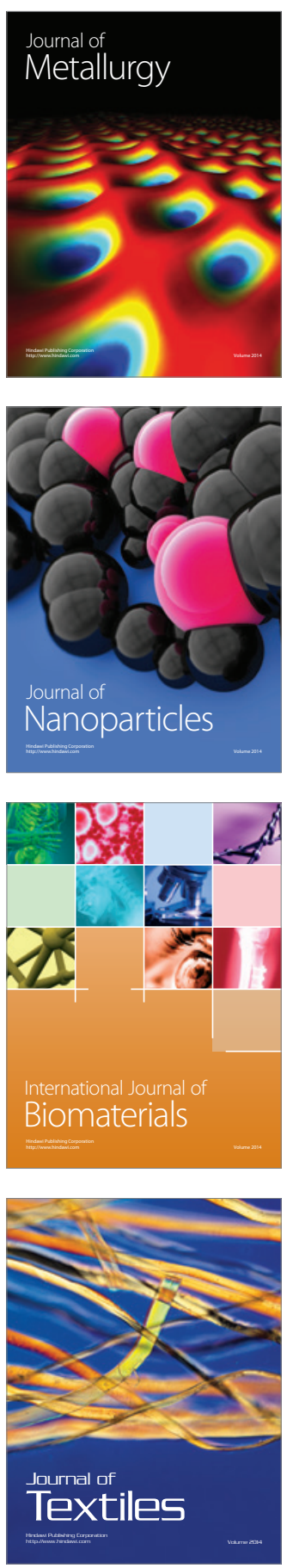